\title{
МЕТОДОЛОГИЧЕСКИЕ ОСНОВЫ ПОВЫШЕНИЯ КАЧЕСТВА ПРОДУКЦИИ И ЭФФЕКТИВНОСТИ ПРОИЗВОДСТВА НА ПРЕДПРИЯТИЯХ СТРОЙИНДУСТРИИ
}

Алироева 3.P.

\author{
ГГНТУ им. акад. М.Д. Миллионщикова, г. Грозный
}

Повышение качества продукции и эффективность производства на предприятиях стройиндустрии приобретает все большее внимание, поскольку эта отрасль сталкивается с многочисленными проблемами. Большинство строительных проектов страдают от снижения производительности и, как следствие, откладывания проектов и перерасхода средств. Цель данной статьи - определить значимость повышения производительности в соответствии с их относительной важностью в строительных проектах. Факторами повышения производительности являются: экономические трудности, политическая ситуация, своевременное выполнение, управление и доступность материалов. Группа внешних обстоятельств признана наиболее важной группой, которая влияет на повышение производительности на предприятиях стройиндустрии, так как нестабильная политическая атмосфера сильно влияет на строительную отрасль. Необходимо установить проактивные отношения между всеми сторонами, чтобы определить эффективные планы повышения производительности.

Ключевые слова: методы, эффективность, производительность, стройиндустрия, предприятие, производство.

Неэффективность, такая как проскальзывание графика и расширение проекта, являются основными причинами перерасхода рабочих мест, что приводит к увеличению средней стоимости на $80 \%$ от первоначальной стоимости.

Хотя многие факторы способствуют перерасходу средств, основным фактором является низкая производительность. «Производительность», обычно определяемая как мера скорости выполнения работ, исторически игнорировалась при строительстве. В то время как в других отраслях, таких как производство, она выросла вдвое, строительство оставалось неизменным на протяжении десятилетий. На самом деле, строительство является одной из немногих отраслей, которые сейчас менее производительны, чем 60 лет назад. Исследователи называют отставание производительности строительства «неразрешимой проблемой производительности» [4, с.155].

Но строительная отрасль начинает уделять первостепенное внимание повышению производительности, поскольку издержки из-за неэффективности продолжают расти. Даже незначительная неэффективность может привести к ошеломляющим затратам. Можно с уверенностью сказать, что обманчиво 
малые разрывы в производительности приводят к непомерным затратам, которые стали просто слишком высокими, чтобы их игнорировать.

Хорошей новостью является то, что если незначительная неэффективность может привести к огромным затратам, то даже постепенное повышение производительности на рабочей площадке может сэкономить подрядчикам много времени и средств.

Повышение производительности работы является ключевым вопросом для предприятий стройиндустрии. В нескольких исследованиях изучались факторы, влияющие на эффективность производства. Опрос главных подрядчиков показал, что некоторые функции, включая практику закупок, контроль затрат, планирование и интеграцию управления, нуждаются в значительном улучшении. Функциями, которые были определены как требующие большего улучшения, были сборка, новые материалы, разработка стоимости, спецификации, доступность рабочей силы, обучение персонала и контроль качества [2, с.172].

Повышение производительности является проблемой управления, и внедрение новых методов или технологий может быть необходимым, но не достаточным условием. Для повышения производительности на предприятиях стройиндустрии необходимо улучшить методы, усовершенствовать программы обучения, улучшить стратегическое управление и улучшить управление.

Отечественные исследователи заявили, что новое управленческое мышление, такое как бережливое производство, предполагает, что повышение производительности может быть достигнуто за счет повышения надежности потоков. Бережливое мышление описывает надежные потоки как своевременную доступность ресурсов, материалов, информации и оборудования.

Предыдущие исследования, касающиеся производительности, показали, что на производительность влияет широкий спектр факторов. Эти факторы можно разделить на отраслевой, корпоративный и проектный уровни. Также было отмечено, что повышение производительности необходимо; если все производственные ресурсы используются надлежащим образом, поскольку капитальные улучшения и повышение производительности идут рука об руку $[5$, c. 124$]$.

Таким образом, было выделено пять ключевых шагов к повышению качества продукции и эффективности производства на предприятии стройиндустрии:

1. Использование группового мышления

Чтобы действительно внести существенные изменения в производственные процессы, требуется командный подход. Привлекая множество дисциплин к поиску улучшенного качества, мы получаем множество точек зрения. Также важно знание истории процесса. Почему процесс такой, какой он есть сегодня? Рассматривая историю и групповую перспективу, можно получить существенные улучшения.

2. Определение качества с точки зрения клиента 
Слишком часто сотрудники производственной среды хотят сделать продукт «лучше». Для этого необходимо использовать точку зрения клиентов, чтобы определить, каким будет лучший в своем классе продукт, и удовлетворить эти требования при минимальных затратах.

3. Развитие организационного понимания стоимости качества

Стоимость устранения дефекта значительно выше, чем стоимость устранения источника проблемы до еe создания. Крайне важно, чтобы производственный персонал был обучен расчету затрат, связанных с гарантийным ремонтом или заменой и стоимостью поврежденной репутации. Когда сотрудники принимают эту точку зрения, желание найти основную причину для решения проблем по своей сути развивается активнее.

4. Искоренение проблемы

Слишком часто улучшения качества производства устраняют симптомы, а не первопричину. Это можно сделать, добавив этапы проверки качества или станции доработки, которые позволяют более эффективно устранять дефекты. Вместо этого в командах должно быть выработано истинное понимание первопричины. Только в том случае, если команды развивают способность определить первопричину дефектов в производственном процессе, создаются истинные решения проблем.

\section{5. Строгая дисциплина}

На протяжении всего процесса улучшения качества важно использовать строгую дисциплину процесса. В зависимости от продукта, который производится, некоторые отклонения могут иметь серьезные последствия для качества [3, с.320].

Когда цель состоит в том, чтобы гарантировать единообразие системы, процесса или продукта, эталонные образцы устанавливаются в документах, называемых стандартами или нормами.

Общими целями стандартов являются упрощение, взаимодействие между вовлеченными сторонами, экономика производства, безопасность и гигиена труда, защита интересов потребителей и устранение торговых барьеров.

В любом типе компании, набор задач, выполняемых предприятием настолько сложен, что они должны обеспечивать внутреннюю согласованность, чтобы убедиться в методичности их применения [1, с.224].

Стандарты устанавливают требования к продуктам или процессам. Они должны включать цель процедуры, ссылки на другие документы, объем, метод и последовательность испытаний, критерии приемки и отклонения, ключевые контрольные точки и время проверки. Во всех случаях контроль процедуры должен быть задокументирован в записях качества и внесен в журнал качества на предприятии стройиндустрии.

Технические или административные процедуры также могут быть частью системы повышения качества. В этом случае руководство содержит общее описание качества системы предприятия, в то время как процедуры, будь то общие или специальные, устанавливают, что необходимо для достижения целей, указанных в руководстве. Стандарты должны включать вовлеченных 
людей, информацию о материалах и оборудовании, a также описание основных видов деятельности.

Таким образом, можно прийти к выводу, что рассматривая взаимосвязь повышения производительности и эффективности производства, производительность труда следует рассматривать как показатель, характеризующий эффективность труда, так и как итоговый, главный показатель экономической эффективности, поскольку каждое изменение в процессе производства находит свое отражение в достигнутом уровне производительности труда.

Исследование выполнено при финансовой поддержке РФФИ в рамках научного проекта № 18-48-200001.

\section{Список литературы}

1. Казакова, Н.В. Экономика и организация инвестирования в строительстве: Учебное пособие / Н.В. Казакова, А.Н. Плотников. - М.: АльфаM, 2018. - 224 c.

2. Михайлов, А.Ю Организация строительства. Стройгенплан / А.Ю Михайлов. - Вологда: Инфра-Инженерия, 2016. - 172 с.

3. Олейник, П.П. Организация, планирование, управление и экономика строительства. Терминологический словарь / П.П. Олейник. - М.: АСВ, 2016. $320 \mathrm{c}$.

4. Русанова, Т.Г. Организация технологических процессов при строительстве, эксплуатации и реконструкции строительных объектов: Учебник / Т.Г. Русанова. - М.: Academia, 2018. - 155 с.

5. Соколов, Г.К. Технология и организация строительства. / Г.К. Соколов. - М.: Academia, 2018. - 124 с. 